\title{
3D spongy-like Au film for highly stable solid contact potentiometric ion selective electrode: application to drug analysis
}

\author{
Emad Mohamed Hussien ${ }^{1} \cdot$ Abeer Rashad Derar ${ }^{1}$
}

(c) Springer Nature Switzerland AG 2019

\begin{abstract}
Potentiometric ion selective electrodes with simple design and high potential stability are required for in-line process, clinical and quality control analysis. The objective of this work is to develop a high-surface-area Au nanostructure solidcontact (SC) platform for high stable ion selective electrode for drug analysis. Memantine, a pharmaceutical compound prescribed for Alzheimer's disease, with challenging measurable analytical characteristics, was selected as a model for this purpose. Internal solid-contact with a high surface area was prepared by direct electrochemical deposition of Aunanostructures onto a Pt electrode ( $500 \mu \mathrm{m}$ diameter and $3 \mathrm{~mm}$ long). The proposed design combines the small size with the high surface area that is necessary for stable potential response. Cyclic voltammetry, impedance electrochemical spectroscopy and chronopotentiometry were used to evaluate electrochemical properties of the Au film. The Au-nanostructure SC electrode was coated with a membrane cocktail containing a lipophilic ion exchanger. The electrode exhibited a Nernstian response $\left(58.5 \pm 1 \mathrm{mV} /\right.$ decade) to memantine over a wide concentration range $\left(1 \times 10^{-5}-1 \times 10^{-2} \mathrm{M}\right)$. The electrode showed high potential stability $(0.03 \mu \mathrm{V} / \mathrm{s})$, wide $\mathrm{pH}$ working range (3.0-8.0) and high selectivity to memantine $\left(\log k_{i, j}^{\text {pot }} \leq-2.38\right)$. The electrode was applied for direct determination of memantine in pharmaceutical dosage form, human urine and surface water with high accuracy $( \pm 2 \%)$ and precision (RSD $\leq 1.5 \%)$.
\end{abstract}

Graphical abstract
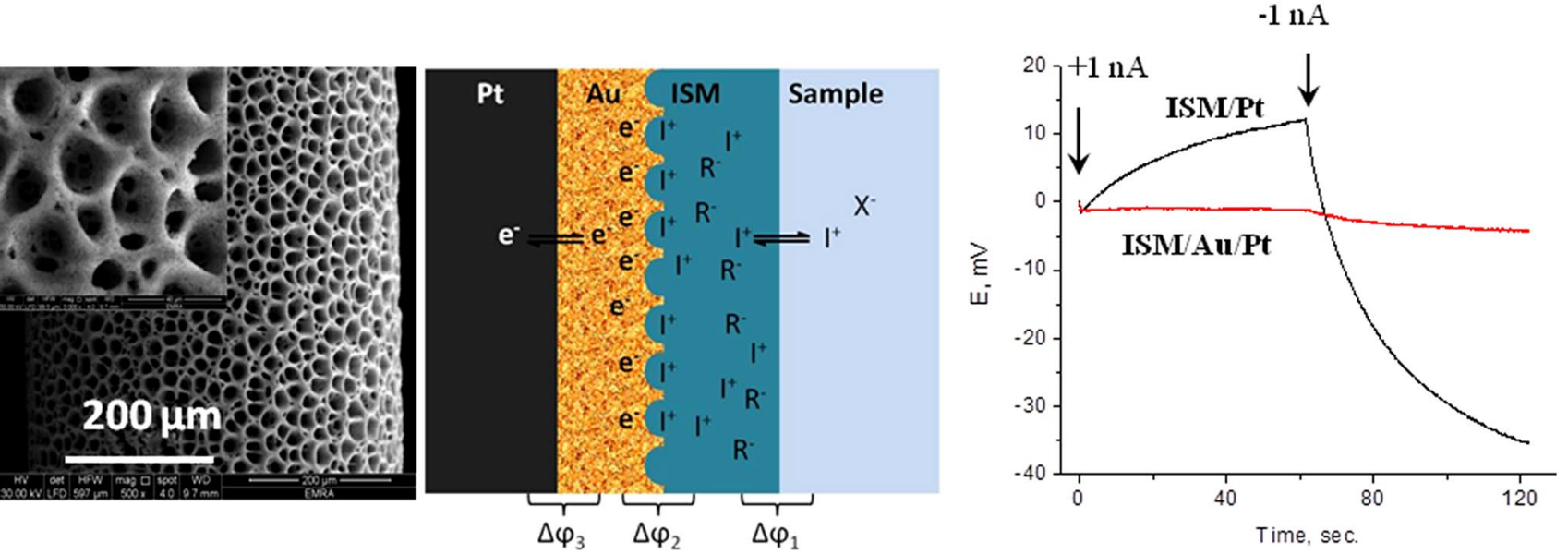

Keywords Highly porous Au film · Au nanostructure · Solid-contact · High potential stability · Memantine ISE

Emad Mohamed Hussien, emadhussien@yahoo.com | 1 Department of Pharmaceutical Chemistry, National Organization for Drug Control and Research (NODCAR), P.O Box 29, 9 Abou-Hazem str, Giza, Egypt.

SN Applied Sciences (2019) 1:338 | https://doi.org/10.1007/s42452-019-0349-z

Received: 11 February 2019 / Accepted: 7 March 2019 / Published online: 13 March 2019 


\section{Introduction}

Memantine is an antagonist of $\mathrm{N}$-methyl-D-aspartate receptors [1]. It is described for treatment of moderate to severe Alzheimer's disease. Memantine is an alicyclic aliphatic compound with a primary amine group (Fig. 1). Direct UV absorption and fluorescence analysis of memantine is challenging due to absence of chromophoric groups and the weak UV absorbance of the primary amine group. Derivatization reactions were proposed to impart measurable characteristics to mematine to enable UV, fluorescence and liquid chromatographic quantification [2-10]. Unfortunately, however, derivatization reactions involve highly reactive compounds that require high precautions and special safety measures. In addition, derivatization reactions add extra steps to the analytical method and, hence, prolong the experimental time scale. Memantine has relatively high thermal stability that has enabled its determination using gas chromatography [11]. The drawback of this method is however the extraction step that uses environmentally unfavorable organic solvents before injection. Other methods including LC-MS/MS $[12,13]$ and HPLC with refractive index $[14,15]$ have been proposed. Obviously, these methods either use expensive instrumentations (LC-MS/MS) or use non selective detector (refractive index). Therefore, developing of simple, rapid and selective analytical method free from derivatization or mandatory extraction steps is demanded.

A simple solution that can meet these requirements is to use ion selective electrodes. Indeed, several conventional PVC membrane ion selective electrodes with different types of ion exchangers were proposed for determination of memantine in pharmaceutical formulation [16-18]. Although the proposed electrodes exhibited a wide linear range with satisfactory sensitivity and selectivity, the liquid contact electrode requires special skills for preparation and handling which limits its application for quality control and on-line process analysis.

On contrary, ion selective electrodes ISEs with an internal solid contact have attracted a great attention over the past decades due to their small size, low cost and ease of preparation [19]. In solid contact ion selective electrodes the internal filling solution which is necessary for conventional ion selective membrane electrode is eliminated, and the sensing membrane is casted directly on electronic conductor. Such configuration manifests potential instability

Fig. 1 Chemical structure of memantine $\mathrm{HCl}$

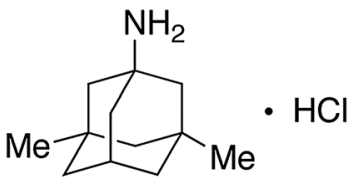

and weak reproducibility due to the absence of stable process that secures a reversible transition between electron and ionic conductivity at the solid contact interface [20, 21]. Great efforts have been devoted over the past decade to enhance potential stability by improving the internal solid contact using carbon based materials[22-25], gold nanoparticles $[26,27]$ and redox substances [28-30]. Most of these approaches have focused on determination of inorganic ions and none of them considered the application to important pharmaceutical compounds.

In this paper, a new all-solid-state ISE based on a highly porous Au nanostructures as ion-to-electron transducer was prepared. The electrode was prepared by one-step electrochemical deposition of Au onto a Pt microelectrode (500 $\mu \mathrm{m}$ diameter and $3 \mathrm{~mm}$ long). The proposed electrode has the advantage of small size, high surface area and large double layer capacitance which are necessary for stable potential response [31]. Memantine was selected as a model pharmaceutical compound for studying the $\mathrm{Au} /$ Pt as a solid contact platform for preparation high stable ion selective electrode for drugs analysis. The ion selective electrode was prepared by dip coating process. The electrode exhibited satisfactory potentiometric characteristics with remarkable potential stability compared to bare $\mathrm{Pt}$ as internal solid contact. The electrode was employed for selective determination of memantine in pharmaceutical dosage form, human urine and surface water. The electrode is suitable for in-line monitoring with high accuracy.

\section{Experimental}

\subsection{Materials}

Memantine hydrochloride (MEM) drug substance (purity $=98 \%$ ) was kindly provided by Techno Pharmaceutical, Alexandria, Egypt. Ebixa Tablets $(10 \mathrm{mg} / \mathrm{tab}$ let) Rottendorf Pharma GmbH, Denmark, was obtained from a local pharmacy. Poly(vinyl chloride) (PVC) of high molecular weight was from Sigma-Aldrich, St. Louis, USA. 2-Nitrophenyl octylether (oNPOE) was purchased from Fluka, Switzerland. Potassium tetrakis(4-chlorophenyl) borate (TCPB) was purchased from Alfa Aesar, Heysham, England. Potassium hexacyanoferrate was from Riedel-De Haen, Hannover, Germany. Hydrogen tetrachloroaurate (III) hydrate $\left(\mathrm{HAuCl}_{4} \cdot \mathrm{H}_{2} \mathrm{O}\right)$ was purchased from Alfa Aesar, Thermofisher, Germany. All reagents were of analytical grade and bidistilled water was used throughout the experiments unless otherwise stated. 


\subsection{Preparation of Au-nanostructure structure solid conatact}

A Pt wire (500 $\mu \mathrm{m}$ diameter and $5 \mathrm{~cm}$ long) was inserted into a capillary glass tube; $3 \mathrm{~mm}$ of the Pt wire was left protruding out at one end of the tube to serve as internal contact solid contact for ion selective electrode preparation. With the Pt wire fixed at this position, the glass tube was heat sealed around it. The other end of the Pt was used for connection to the instrument. The Pt was cleaned using diamond polishing suspension $15.0 \mu \mathrm{m}, 3.0 \mu \mathrm{m}$ and $1.0 \mu \mathrm{m}$ (BASi, USA). Au nanostructures were deposited by applying a potential of $-3.0 \mathrm{~V}$ in $5.0 \mathrm{mM} \mathrm{HAuCl}_{4}$ for $90 \mathrm{Sec}$. [27], The Au-nanostructures/Pt wire was dipped into the membrane cocktail several times to get a uniform plastic film. The membrane cocktail consists of $33.0 \mathrm{wt} \%$ PVC of high molecular weight, $1 \mathrm{wt} \%$ potassium tetrakis (4-chlorophenyl)borate and $66 \mathrm{wt} \%$ 2-Nitrophenyl octylether in THF. The ISM/Au-nanostructure/Pt electrode was left for $24 \mathrm{~h}$ at room temperature to allow solvent evaporation. Afterwards, the electrode was conditioned for $12.0 \mathrm{~h}$ in $1 \times 10^{-3} \mathrm{M}$ memantine $\mathrm{HCl}$, unless otherwise stated.

\subsection{Morphological characterization}

Scanning electron microscopy (FEl Company, Netherlands) was used for the morphological characterization of the Au-nanostructure layer. No sample pre-treatment was performed prior to SEM imaging. The SEM analysis was carried out at the Central Laboratories Sector of The Egyptian Mineral Resources Authority using SEM Model Quanta 250 FEG (Field Emission Gun) with accelerating voltage $30.0 \mathrm{~K} . V$. ., magnification $14 \mathrm{x}$ up to $1,000,000$ and resolution for Gun.1n.

\subsection{Electrochemical measurements}

\subsubsection{Potentiometric measurements}

All potentiometric measurements were performed using a Jenway $3510 \mathrm{pH} / \mathrm{mV}$ meter (England) and $\mathrm{Ag} / \mathrm{AgCl}$ (3 M) as a reference electrode. The potentiometric response of the electrode was studied in the concentration range from $1 \times 10^{-6}$ to $1 \times 10^{-3} \mathrm{M}$ memantine $\mathrm{HCl}$ by successive addition of memantine $\mathrm{HCl}\left(1 \times 10^{-2} \mathrm{M}\right)$ to $50.0 \mathrm{~mL}$ bidstilled water. Potential of higher concentrations $\left(5 \times 10^{-3}\right.$ and $1 \times 10^{-2} \mathrm{M}$ ) were recorded by dipping the electrode in each solution separately. The calibration graphs were constructed by plotting the electrode potential vs. - log [conc., M]. The $\mathrm{pH}$ sensitivity of the electrode was studied for $1 \times 10^{-4}$ and $1 \times 10^{-3} \mathrm{M}$ memantine $\mathrm{HCl}$ by changing the $\mathrm{pH}$ of the solution using $\mathrm{HCl}$ and $\mathrm{NaOH}, 0.01 \mathrm{M}$ each. The $\mathrm{pH}$ change was recorded using a Cyberscan 500 digital pH meter (Eutech Instruments, Thermo Scientific, USA). The selectivity was studied using fixed interference method [32]. In this method, the potential of the electrode is measured in a solution of constant concentration of the interfering ion $\left(1 \times 10^{-2} \mathrm{M}\right)$ and varying concentration of the target ion (memantine). The potential of the electrode was plotted against the logarithm of the concentration of memantine. The intersection of the extrapolation of the linear portions of this plot indicates memantine concentration which is used to calculate the selectivity coefficient by the Nikolsky-Eisenman equation [32]. The electrode was stored in $1 \times 10^{-3} \mathrm{M}$ memantine $\mathrm{HCl}$ solution and kept at room temperature between measurements. All potential measurements were recorded under constant stirring at room temperature $\left(25.0 \pm 1{ }^{\circ} \mathrm{C}\right)$.

\subsubsection{Cyclic voltammetry}

The cyclic voltammetric (CV) measurements were performed using SP-150 potentiostat (BioLogic Science Instrument, France) provided with EC-Lab (windows v11.02) software. A Pt auxiliary electrode and $\mathrm{Ag} / \mathrm{AgCl}$ reference electrode $(3 \mathrm{M} \mathrm{KCl})$ were purchased from BASi (USA). The $\mathrm{CV}$ was recorded in a $5.0 \mathrm{mM}$ hexacyanoferrate aqueous solution.

\subsubsection{Electrochemical impedance spectroscopy (EIS)}

The EIS was performed using the same SP-150 potentiostat and EC-Lab software that was used for CV studies. The impedance spectra were recorded in the frequency range from $20 \mathrm{kHz}-0.1 \mathrm{~Hz}$. using a sinusoidal excitation signal (amplitude $= \pm 10 \mathrm{mV}$ ) superimposed on the electrode potential $(E=220 \mathrm{mV})$ in $5.0 \mathrm{mM}$ hexacyanoferrate aqueous solution. The charge transfer resistance was determined from the complex impedance plot (Imaginary $Z$ versus Real $Z$ ) by fitting a circle through the points that represent the electrode-solution interphase using the ECLab software.

\subsubsection{Chronopotentiometric studies}

Constant current potentiometric measurements were performed using the same potentiostat. A constant current of $\pm 1.0 \mathrm{nA}$ was applied for $60 \mathrm{~s}$ each, while monitoring the electrode potential. The measurements were performed in $1 \times 10^{-3} \mathrm{M}$ memantine $\mathrm{HCl}$ at room temperature. 


\subsection{Sample preparations and analytical applications}

\subsubsection{Pharmaceutical dosage form}

Fifteen tablets of memantine hydrochloride were finely ground in a mortar. An accurately weighed amount of the powder (equivalent to $108 \mathrm{mg}$ memantine $\mathrm{HCl}$ ) was transferred to $50-\mathrm{mL}$ measuring flask, dissolved in $25.0 \mathrm{ml}$ bidistilled water and sonicated for $15 \mathrm{~min}$. The flask was completed to mark with bidistilled water; this solution was marked as stock sample solution. Sample solutions (50.0 mL each) with different concentrations were prepared by dilution from the stock sample solution. The concentration of memantine in each solution was determined by the standard addition method [33].

\subsubsection{Spiked human urine}

Human urine was taken from healthy donors and used shortly after collection. Urine samples were used without pretreatment. Spiked human urine was prepared by spiking $5.0 \mathrm{ml}$ urine with memantine hydrochloride and diluting to $50.0 \mathrm{~mL}$ using bidistilled water.

\subsubsection{Tap water}

Spiked tap water was prepared by spiking tap water $(50.0 \mathrm{~mL}$ ) with $108 \mathrm{mg}$ memantine $\mathrm{HCl}$. Stock sample solution and sample solutions with different concentrations were prepared as in the pharmaceutical dosage form.

\section{Results and discussion}

\subsection{Characterization of the Au/Pt electrode}

\subsubsection{Morphology of the solid contact}

Figure 2 shows an SEM picture of Au film electrochemically deposited onto a $500 \mu \mathrm{m}$ diameter Pt wire. The thickness of

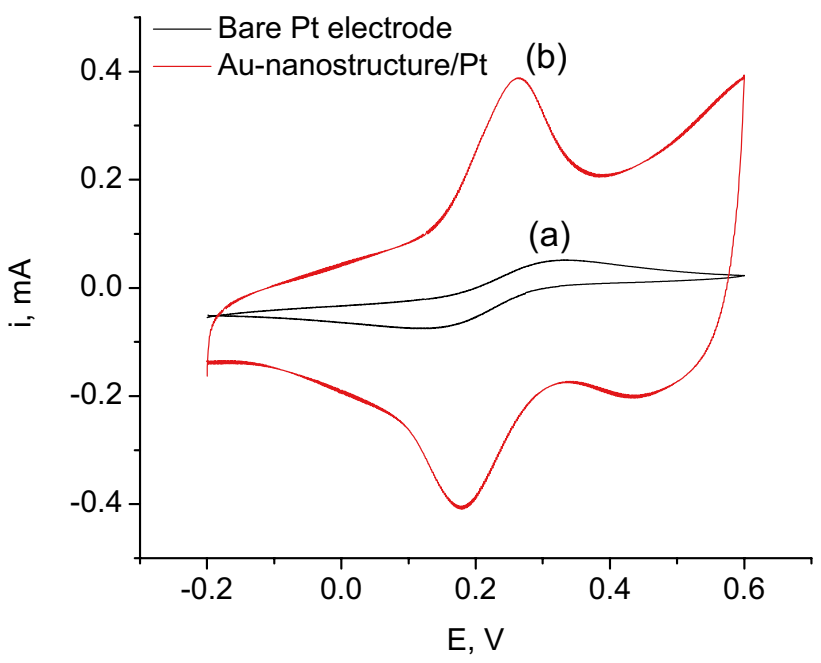

Fig. 3 Cyclic voltammograms for (a) Pt and (b) Au-nanostructure/Pt electrodes in $5.0 \mathrm{mM}$ hexacyanoferrate solution in $100 \mathrm{mM} \mathrm{KCl}$ at $100 \mathrm{mV} / \mathrm{s}$ scan rate

the Au film is estimated to be $\leq 17 \mu \mathrm{m}$ (calculated from the Pt diameter before and after deposition) (Fig. 2A). The Au film is highly porous with a pore diameter ranging from $20 \mu \mathrm{m}$ down to a few nanometers for small pores (Fig. 2B). Figure $2 \mathrm{C}$ shows that the surface of the film is coral-like surface with remarkable Au-nanostructures. Such morphology reflects the high surface area of the electrodeposited Au film.

\subsubsection{Cyclic voltammetric}

Typical cyclic voltammograms for Pt and Au-nanostructure/Pt electrodes in hexacyanoferrate solution is shown in Fig. 3. As it can be seen from the CV, the capacitive current of the Au-nanostructure/Pt electrode is higher than that of bare Pt electrode. This confirms the high surface area of the Au-nanostructure/Pt electrode compared to bare Pt electrode. It is observed that the reduction peak is slightly shifted to more positive potential and the oxidation peak is slightly shifted towards
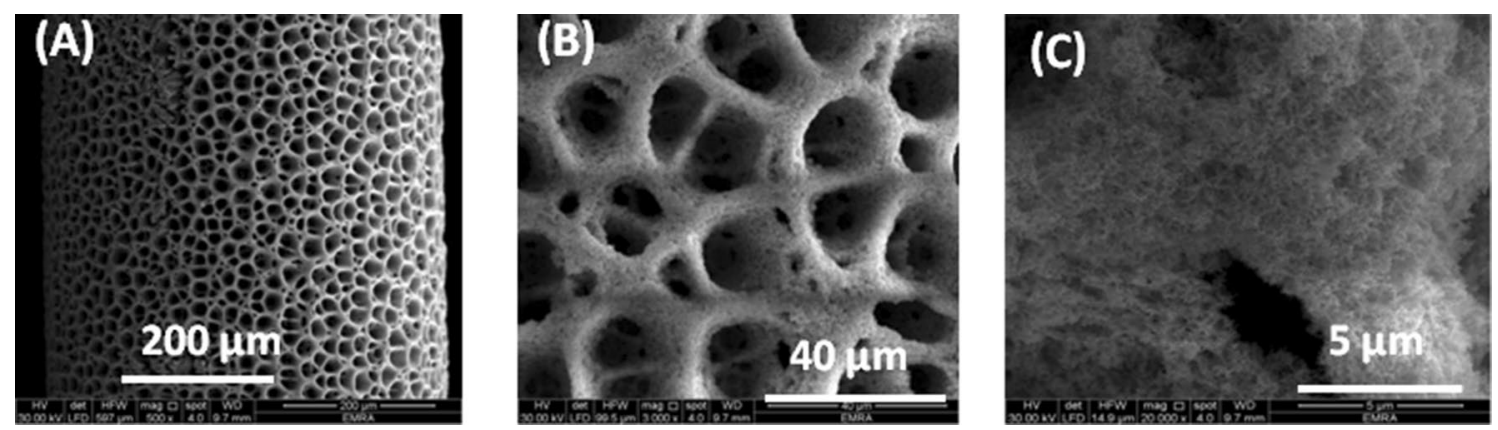

Fig. 2 SEM image of (A) Pt wire (500 $\mu$ m diameter) with electrodeposited Au-nanostructures

SN Applied Sciences 
more negative potential. As a result, the peak to peak separation is reduced from $200 \mathrm{mV}$ for Pt electrode to $80 \mathrm{mV}$ for Au-nanostructure/Pt electrode suggesting fast electron transfer for the Au-nanostructure/Pt electrode. The current of the reduction and oxidation peaks are peak shaped. This is due to the depletion of the hexacyanoferrate within the pores of the Au-nanostructure/ Pt before it becomes diffusion limited at the electrode surface indicating the high porosity of the Au-nanostructure/Pt structure.

\subsubsection{EIS}

Electrochemical impedance spectra were conducted for the Pt and Au-nanostructure/Pt electrodes (Fig. 4). The impedance spectrum of the Pt electrode showed a high frequency semicircle arising from the charge transfer resistance in parallel with the double layer capacitance of the electrode. The charge transfer resistance was estimated

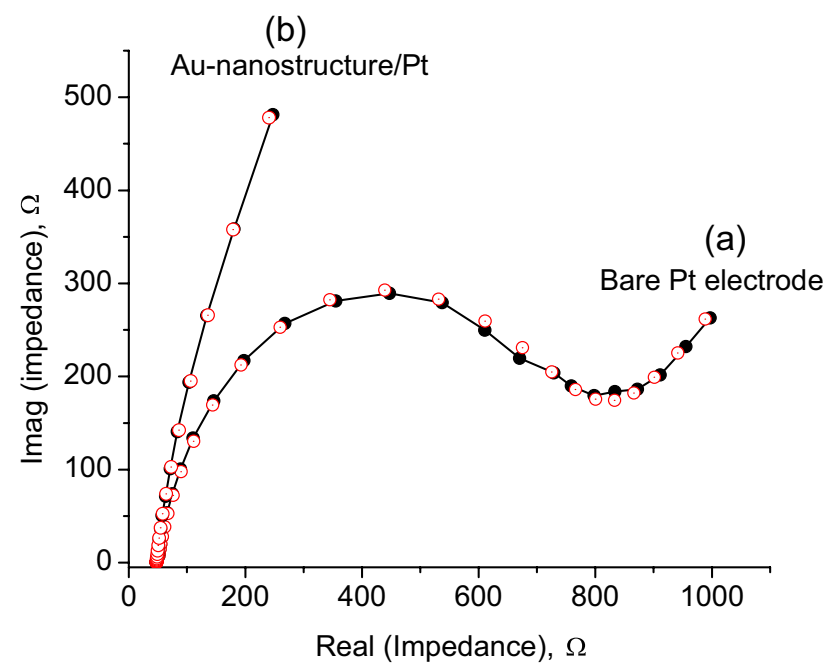

Fig. 4 Impedance spectra recorded for (a) Pt and (b) Au-nanostructure/pt electrodes in $5.0 \mathrm{mM}$ hexacyanoferrate solution. The spectra are recorded at $\mathrm{E}_{\mathrm{dc}}=0.22 \mathrm{mV}$ and $\mathrm{ac}= \pm 10 \mathrm{mVpp}$ in the frequency range from $20 \mathrm{kH}$ to $0.1 \mathrm{~Hz}$. Open red circles represent the fitted values to be $700 \mathrm{Ohm}$. In contrast, the high frequency semicircle disappeared in case of Au-nanostructure/Pt indicating an easy electron transfer. While, a slightly curved line was observed at low frequency; most likely due to the high double layer capacitance of the Au/solution interface. The high double layer capacitance is due to the high surface of the electrodeposited Au film. These results are in consistence with the surface morphology revealed by SEM and the electrochemical properties obtained by CV.

\subsubsection{Response characteristics of the ISM}

ISMs with different compositions were prepared and calibrated using pure memantine solution. The effect of ISM composition on the potential response is summarized in Table 1. All electrodes gave linear response with a Nernstian slope between 57.0 and $59.5 \mathrm{mV} /$ decade over the concentration range from $1 \times 10^{-5}$ to $1 \times 10^{-2}$ with nearly comparable detection limit $2.5 \times 10^{-6}$. Also, the effect of ISM thickness on the potentiometric response was investigated. ISMs with different thickness were obtained by repeatedly (3, 4 and 5 times) dipping the electrode in the membrane composition solution. The variation in membrane thickness, as a result of increasing number of dipping, showed no significant effect on the magnitude of the potentiometric response. Therefore, in this work a coated wire electrode formed by repeatedly dipping (4 times) the electrode in the membrane composition was chosen as optimal membrane thickness for further characterizations. Figure 5 shows the calibration curve and the corresponding potentimetric time trace of the electrode. From the potential time trace curve it is clear that the electrode exhibited a fast response time; a stable potential response was obtained $\leq 10 \mathrm{~s}$.

\subsubsection{Chronopotentiometric measurements}

The potential stability of the proposed SC electrode was investigated using reversal current chronopotentiometry. In this method an external current was applied to the electrode while the electrode potential was monitored.
Table 1 Potentiometric response of memantine allsolid-state ISE with variable composition

\begin{tabular}{|c|c|c|c|c|c|c|c|}
\hline \multirow[t]{2}{*}{ Electrode } & \multicolumn{7}{|c|}{ \%Composition (w/w) } \\
\hline & Plasticizer & PVC & TCPB & $\begin{array}{l}\text { Slope } \pm \text { SD, } \\
\mathrm{mV} / \text { decade }^{\mathrm{a}}\end{array}$ & Linearity, $\mathrm{M}$ & $\mathrm{DL}, \mathrm{M}$ & $r^{2}$ \\
\hline I & 33.0 & 66.5 & 0.5 & $57.0 \pm 1.2$ & $\begin{array}{r}5.0 \times 10^{-5}- \\
1.0 \times 10^{-2}\end{array}$ & $3.3 \times 10^{-6}$ & 0.9987 \\
\hline II & 33.0 & 66.0 & 1.0 & $58.7 \pm 0.9$ & $\begin{array}{r}1.0 \times 10^{-5}- \\
1.0 \times 10^{-2}\end{array}$ & $2.5 \times 10^{-6}$ & 0.9991 \\
\hline III & 33.0 & 65.5 & 1.5 & $57.7 \pm 0.6$ & $\begin{array}{r}5.0 \times 10^{-5}- \\
1.0 \times 10^{-2}\end{array}$ & $4.0 \times 10^{-6}$ & 0.9989 \\
\hline
\end{tabular}

${ }^{\text {aThree determinations }}$ 
Fig. 5 Potentiometric time trace obtained during the calibration of memantine using the Au/Pt electrode (A) and corresponding calibration graph (B)

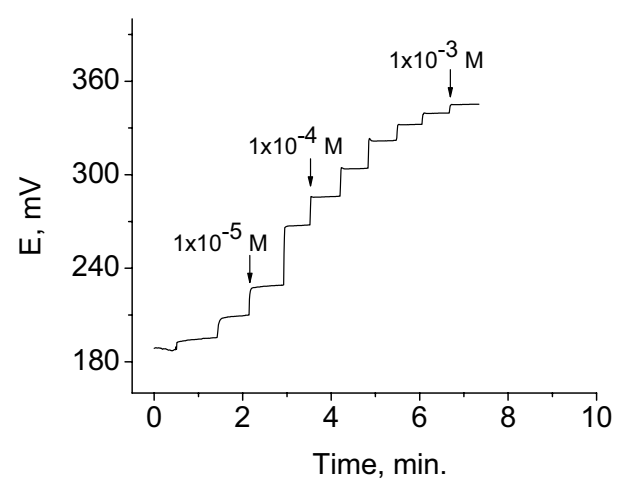

(A)

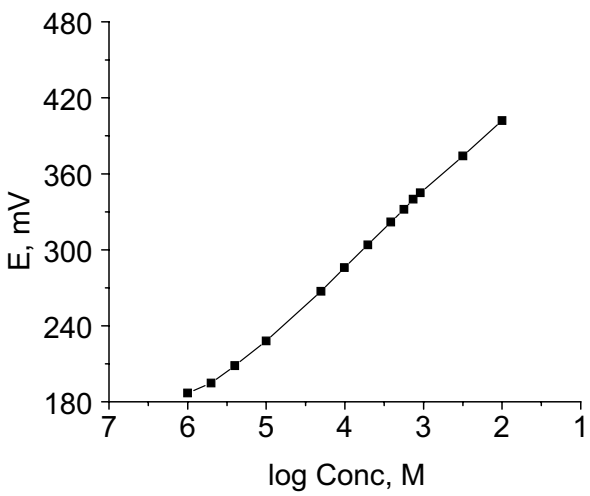

(B)

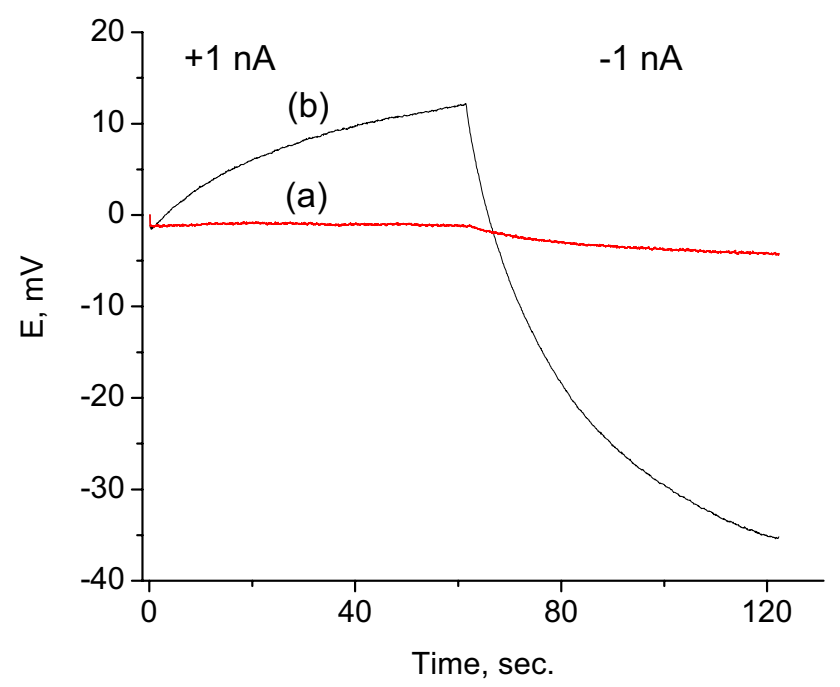

Fig. 6 Chronopotentiograms for memnatine ISEs: (a) ISM/Au-nanostructuer/Pt and (b) ISM/Pt electrodes. Applied current: $+1 \mathrm{nA}$ for $60 \mathrm{~s}$ and $-1 \mathrm{nA}$ for $60 \mathrm{~s}$

Figure 6 shows the effect of an external current of $\pm 1 \mathrm{nA}$ on the potential stability of ISM/Pt and ISM/Au-nanostructure/Pt electrodes. It is clear that the potential stability of the electrode is improved in presence of Au layer as interface relative to bare $\mathrm{Pt}$ wire. This phenomenon is attributed to the electrical double capacitance where the $\mathrm{Au}$ - nanostructurere represents an electrical capacitor with one side carries charge in the form of ions from the ISM and the other side formed by electrons from the solid contact $[23,31]$. The higher double layer capacitance is due to the high surface area provided by the spongy-like structure of the Au layer. The effect of increasing the interfacial ISM/SC on the potential stability has been previously reported for inorganic ions [22-25, 34].

\subsubsection{Potential stability}

The potential stability of the electrode was investigated by monitoring the potential of the electrode in $1 \times 10^{-3}$ $\mathrm{M}$ memantine $\mathrm{HCl}$ for $60 \mathrm{~min}$. The ISM/Au-nanostructure/ Pt electrode showed a very high stable potential with a potential drift limited to $0.03 \mu \mathrm{V} / \mathrm{s}$. Whereas, the ISM/ Pt electrode showed a positive drift of $6 \mu \mathrm{V} / \mathrm{s}$ (200 times higher than that for the ISM/Au-nanostructure/Pt electrode). Moreover, the potential stability and reproducibility was tested daily over 7 days. The ISM/Au-nanostructure/ Pt showed a high reproducibility, the electrode retained its initial potential (within $\pm 2 \mathrm{mV}$ variation) after 7 days. On the other hand, the ISM/Pt electrode exhibited a great nonlinear potential shift. About $+60 \mathrm{mV}$ shift in potential reading was observed after $24 \mathrm{~h}$, and $+95 \mathrm{mV}$ shift was observed after 2 days. This instability of the ISM/Pt is due to the poor double layer capacitance of the ISM/Pt interface. The potential stability is shown in (Fig. 7).

\subsubsection{Memory effect and reproducibility}

Electrode memory occurs when the potential reading of the electrode in a given concentration of the analyte is not obtained again after exposing the electrode to another different concentration of the same target analyte. Here, the ISM/Au-nanostructure/Pt electrode was exposed alternately to memantine solutions of $1 \times 10^{-3}$ and $1 \times 10^{-4} \mathrm{M}$ for 1 min each (Fig. 8A). As a result, the electrode potential was immediately dropped and jumped alternately by a value of $57.5 \pm 1.0 \mathrm{mV}$, indicating a high reproducibility of the ISM/Au-nanostructure/Pt electrode with negligible hysteresis. Moreover, the electrode was exposed to bidistilled water and then again to $1 \times 10^{-3} \mathrm{M}$ memantine solution. The difference between the potential values reported before and after exposing to water was negligible $( \pm 1 \mathrm{mV})$. 

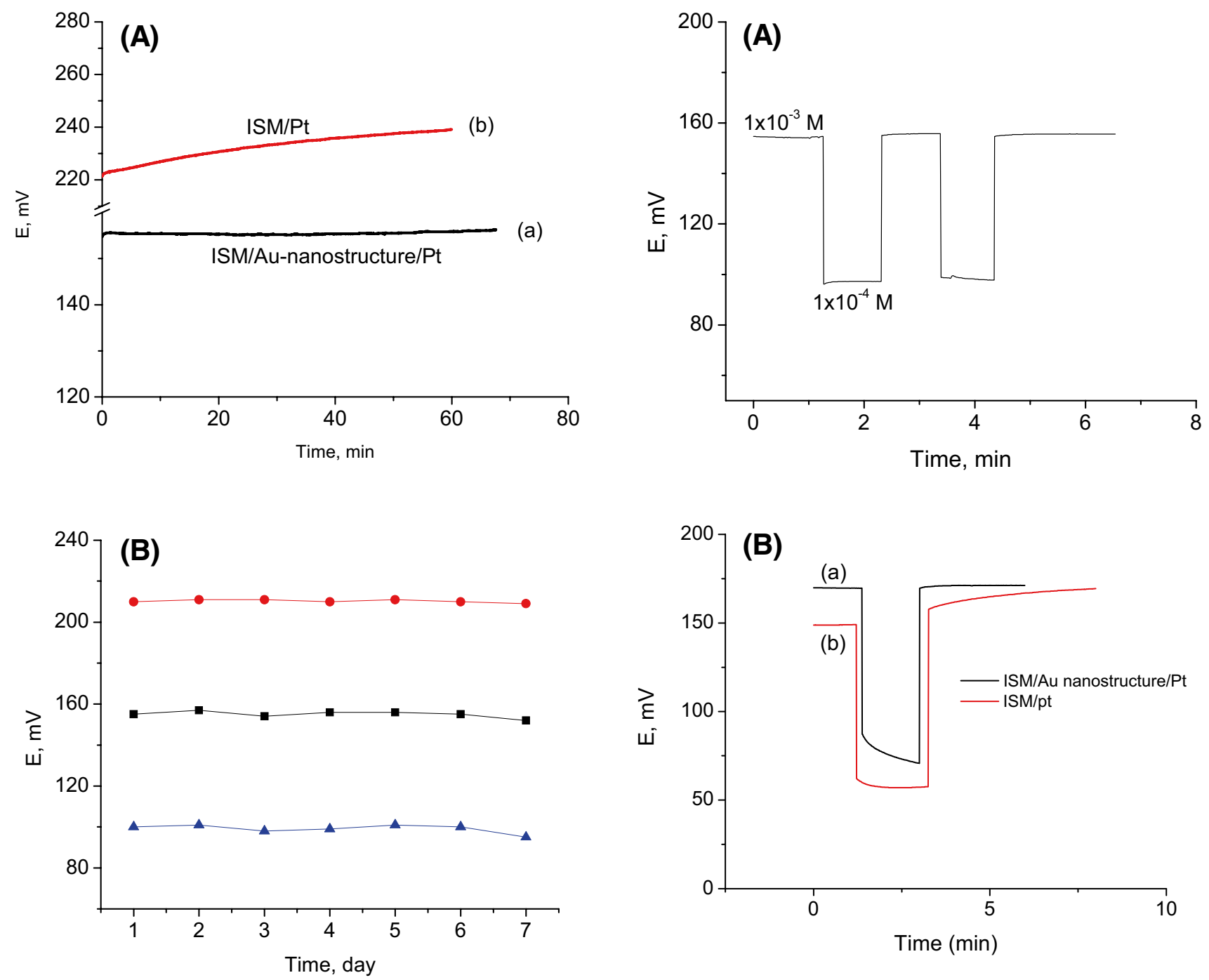

Fig. 7 (A) Potential stability of ISM/Pt and ISM/Au-nanostructure/Pt electrodes in $1 \times 10^{-3} \mathrm{M}$ memantine $\mathrm{HCl}$ over $60 \mathrm{~min}$. (B) the potential stability of ISM/Au-nanostructure/Pt electrode over 7 days (3 electrodes)

In contrast, the ISM/Pt failed to retain its potential after exposing to water. A potential difference of $16 \mathrm{mV}$ was observed when the electrode was exposed to water for $1 \mathrm{~min}$, indicating a high hysteresis and, hence, poor reproducibility of the ISM/Pt electrode (Fig. 8B).

\subsubsection{Effect of PH}

The effect of changing the $\mathrm{pH}$ of memantine solutions $1 \times 10^{-3} \mathrm{M}$ and $1 \times 10^{-4} \mathrm{M}$ on the potential response of the electrode is shown in (Fig. 9). The potential of the electrode is not affect by changing the $\mathrm{pH}$ of the solution

Fig. 8 Hysteresis and reproducibility: (A) ISM/Au-nanostructure/ Pt electrodes with alternate change of memantine concentrations and (B) ISM/Pt and ISM/Au-nanostructure/Pt electrodes in $1 \times 10^{-3}$ $M$ memantine solution and water

in the $\mathrm{pH}$ range from 3.0 to 8.0. A slight response to $\mathrm{H}^{+}$ was observed at $\mathrm{pH} \leq 3.0$. Whereas, a dramatic change in the potential response of the electrode was observed at $\mathrm{pH} \geq 8.0$; this is due to deprotonation and precipitation of memantine as a base at higher $\mathrm{pH}$ values.

\subsubsection{Selectivity}

The influence of an interfering ion on the electrode response can be quantified by means of a selectivity coefficient $k_{i, j}^{p o t}$. A high value of $k_{i, j}^{\text {pot }}$ refers to a high con- 


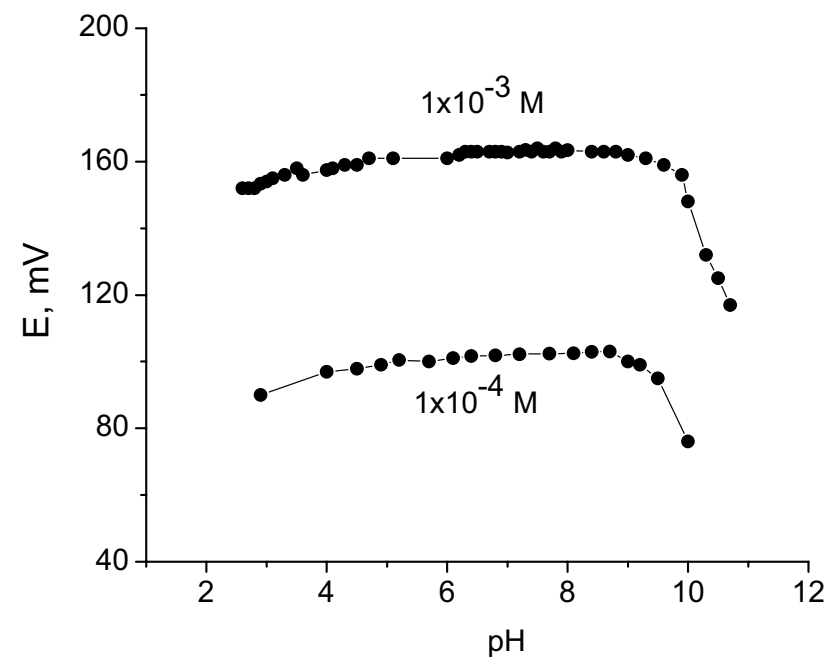

Fig. 9 Effect of $\mathrm{pH}$ of on the electrode response for ISM/Au-nanostructure/Pt electrode

Table 2 Potentiometric selectivity coefficient of memantine all-solid-state ISE

\begin{tabular}{ll}
\hline Interferent & $\log k_{i, j}^{\text {pot }}$ \\
\hline $\mathrm{K}^{+}$ & -2.70 \\
$\mathrm{Na}^{+}$ & -2.52 \\
$\mathrm{Ca}^{2+}$ & -2.32 \\
$\mathrm{Mg}^{2+}$ & -2.11 \\
$\mathrm{NH}_{4}^{+}$ & -3.10 \\
$\mathrm{Mannitol}^{+}$ & -2.76 \\
Aspartam & -2.83 \\
DL-Lysine $\mathrm{HCl}$ & -2.62 \\
L-Arginine $\mathrm{HCl}$ & -2.52 \\
L-Leucine & -2.48 \\
L-Alanine & -2.38 \\
\hline
\end{tabular}

tribution of an interfering ion to the electrode potential. In this work, the selectivity coefficient was determined by the fixed interference method [32]. The selectivity coefficients are reported in Table 2 . The selectivity coefficients are tabulate as logarithm of $k_{i, j}^{\text {pot }}$ due to the low values of $k_{i, j}^{\text {pot }}$. It is clear that the electrode has a high selectivity to memantine over the tabulated interfering compounds.

\subsubsection{Analytical application}

The proposed electrode was applied successfully for determination of memantine in drug substance, pharmaceutical dosage form, spiked human urine and and using the standard addition method. The high stability and fast response time of the solid contact enabled satisfactory accuracy and precision. The accuracy of the potentiometric measurements was investigated by determination of memantine at five different concentration levels $4.32,8.64,12.96,17.28$ and $21.60 \mu \mathrm{g} / \mathrm{mL}$. The mean recovery data obtained at each concentration level was within $\pm 2 \%$. The $\% R S D(n=5)$ calculated at each level was $\leq 1.5 \%$. Table 3 summarizes the accuracy and precision of the ISM/Au-nanostructure/Pt electrode for determination of memantine in the drug substance and pharmaceutical formulation. The accuracy and precision of the proposed method was compared statistically to that of an official method by calculating the student t- and F-ratio tests. In the official method [11], the sample was treated by sodium hydroxide and extracted by toluene followed by injection in GC instrument. Atypical GC chromatogram is shown in supplementary information: Fig. 10. The sample was repeated six times and the mean of the results was compared to that of the proposed method using the $\mathrm{t}$-test. The calculated $\mathrm{t}$ value was less than the tabulated value at 95 confidence limit; indicating that the two methods are equivalent.

The precision of the two methods were compared using the F-ratio test. The calculated $\mathrm{F}$ value is less than the tabulated one at $95 \%$ confidence indicating that the precision of the proposed method is equivalent to the official one.

The potentiometric method was extended for determination of memantine in spiked human urine and tap water. Previous results showed that the execreted memantine concentration in urine is between 2 and $4 \mu \mathrm{g} / \mathrm{mL}$ (in time interval between 25 and $75 \mathrm{~h}$ ) [7], which is suitable for potentiometrc quantification limit. The electrode was also employed for determination of memantine in spiked drinking tap water. The accuracy and precision are presented in Table 3.

\section{Conclusion}

A solid contact ion selective electrode with high surface area was investigated as a platform for stable potential ion selective electrodes for drug analysis. The internal solid contact was prepared by electrochemical deposition of Au layer onto a Pt microelectrode $(500 \mu \mathrm{m}$ diameter and $3 \mathrm{~mm}$ long). The SEM revealed that the Au layer is highly porous with a coral-like surface morphology that guarantees a high solid contact surface area. The electrochemical properties of the Au layer was 
Table 3 Accuracy and precision of memantine all-solid-state ISE for determination of memantine in pharmaceutical dosage form, spiked human urine and tap water

\begin{tabular}{|c|c|c|c|c|c|}
\hline & $\begin{array}{l}\text { Taken } \\
\mu \mathrm{mg} / \mathrm{mL}\end{array}$ & $\begin{array}{l}\text { Found } \pm S D \\
\mu \mathrm{mg} / \mathrm{mL}\end{array}$ & $\begin{array}{l}\text { Recovery } \\
\%\end{array}$ & $\begin{array}{l}\mathrm{RSD}^{\mathrm{a}} \\
\%\end{array}$ & $\begin{array}{l}\text { Official method } \\
\text { Recovery } \pm \% \mathrm{RSD}^{\mathrm{a}}\end{array}$ \\
\hline \multirow[t]{5}{*}{ MEM drug substance } & 4.32 & $4.24 \pm 0.044$ & 98.08 & 1.04 & \\
\hline & 8.64 & $8.57 \pm 0.053$ & 99.19 & 0.62 & \\
\hline & 12.96 & $12.85 \pm 0.167$ & 99.12 & 1.30 & \\
\hline & 17.28 & $16.94 \pm 0.226$ & 98.06 & 1.33 & \\
\hline & 21.6 & $21.35 \pm 0.201$ & 98.86 & 0.94 & \\
\hline \multirow[t]{5}{*}{ Memantine tablet } & 4.32 & $4.20 \pm 0.063$ & 97.21 & 1.50 & \\
\hline & 12.96 & $12.56 \pm 0.159$ & 96.93 & 1.26 & \\
\hline & 21.6 & $20.69 \pm 0.226$ & 95.77 & 1.09 & $96.5 \pm 1.2$ \\
\hline & & t-test & 1.26 & & \\
\hline & & F-ratio test & 2.91 & & \\
\hline \multirow[t]{3}{*}{ Spiked human urine } & 12.96 & $12.32 \pm 0.237$ & 95.05 & 1.92 & \\
\hline & 17.28 & $16.52 \pm 0.239$ & 95.58 & 1.44 & \\
\hline & 21.6 & $20.39 \pm 0.275$ & 94.39 & 1.35 & \\
\hline \multirow[t]{3}{*}{ Spike tap water } & 12.96 & $12.68 \pm 0.225$ & 97.86 & 1.77 & \\
\hline & 17.28 & $16.87 \pm 0.237$ & 97.63 & 1.40 & \\
\hline & 21.6 & $21.35 \pm 0.201$ & 98.86 & 0.94 & \\
\hline
\end{tabular}

${ }^{\text {a Relative standard deviation }(n=5)}$

${ }^{\text {b }}$ Tabulated t-value for $P=0.05$ and 5 degrees or freedom is 2.57

'Tabulated F-value for $\mathrm{n}_{1}=\mathrm{n}_{2}=5$ is 5.05

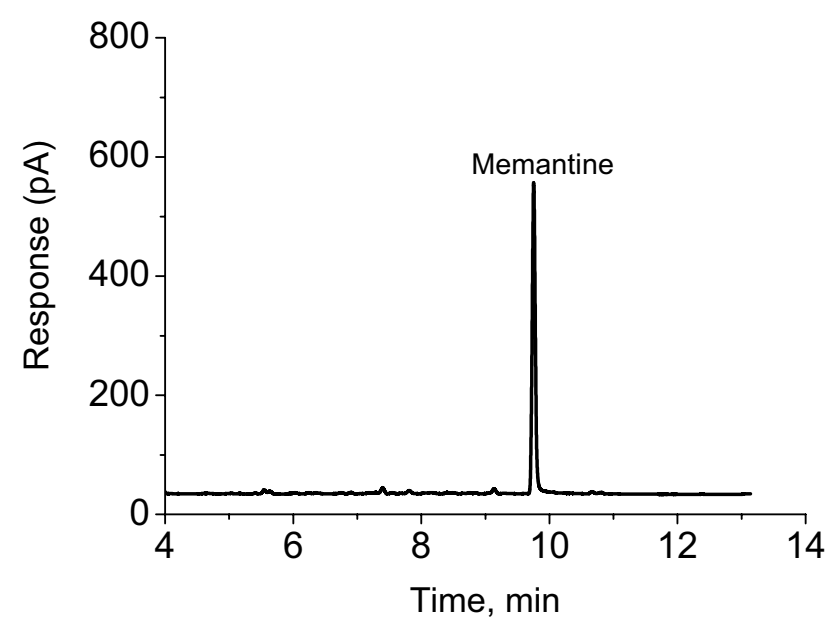

Fig. 10 Typical GC chromatogram for separation of memantine

characterized by cyclic voltammetry, electrochemical impedance spectroscopy and reversal current chronopotentiometry. The results showed that $\mathrm{Au} / \mathrm{Pt}$ solid contact electrode has large double layer capacitance, fast charge transfer and high potential stability compared to the bare Pt solid contact electrode. The electrode exhibited a Nernstian response of $58.5 \pm 1 \mathrm{mV} /$ decade over a wide concentration range of memantine with high potential reproducibility and selectivity for memantine. The electrode is small in size, portable and can be produced on a large scale using screen printed technology. The electrode was used for determination of memantine in pharmaceutical dosage form, spiked urine and tap water with high accuracy and precision.

\section{Compliance with ethical standards}

Conflict of interest On behalf of all authors, the corresponding author states that there is no conflict of interest.

\section{References}

1. Martindale (2009) The complete drug reference. In: Thirtysixth (Edn), Royal Pharmaceutical Society of Great Britain: RPS

2. Puente $B$, Hernandez E, Perez S, Pablo L, Prieto E, Garcia MA, Bregante MA (2011) Determination of memantine in plasma and vitreous humour by HPLC with precolumn derivatization and fluorescence detection. J Chromatogr Sci 49:745-752. https://doi.org/10.1093/chrsci/49.10.745

3. Toker SE, Sagirli O, Cetin SM, Onal A (2011) A new HPLC method with fluorescence detection for the determination of memantine in human plasma. J Sep Sci 34:2645-2649. https ://doi.org/10.1002/jssc.201100489

4. Haen E, Koeber R, Klunemann HH, Waimer R, Kostlbacher $A$ Wittmann M, Brandl R, Dorfelt A, Jahner T, Melchner D (2012) Implementation of a cost-effective HPLC/UV approach for 
routine medical quantification of memantine in human serum. Ther Drug Monit 34:702-712. https://doi.org/10.1097/ FTD.0b013e31826933ab

5. Hassan MG, Emara KM, Mohamed HA, Abdel-Wadood HM, Ikeda R, Wada M, Kuroda N, Nakashima K (2012) Determination of memantine in rat plasma by HPLC-fluorescence method and its application to study of the pharmacokinetic interaction between memantine and methazolamide. Biomed Chromatogr 26:214-219. https://doi.org/10.1002/bmc.1648

6. del Rio-Sancho S, Serna-Jimenez CE, Calatayud-Pascual MA, Balaguer-Fernandez C, Femenia-Font A, Merino V, Lopez-Castellano A (2013) High-performance liquid chromatographic ultraviolet determination of memantine hydrochloride after in vitro transdermal diffusion studies. J Chem. https://doi. org/10.1155/2013/502652

7. Michail K, Daabees H, Beltagy $Y$, Abd Elkhalek M, Khamis M (2013) High-performance liquid chromatographic determination of memantine in human urine following solid-phase extraction and precolumn derivatization. J AOAC Int 96:13021307. https://doi.org/10.5740/jaoacint.11-080

8. Prapatpong P, Techa-In T, Padungpuak W, Buranaphalin S, Suntornsuk L (2015) HPLC-fluorescent analysis of memantine: an investigation on fluorescent derivative formation. J Chem. https ://doi.org/10.1155/2015/672183

9. Dousa M, Pivonkova V, Sykora D (2016) Optimization of o-phtaldialdehyde/2-mercaptoethanol postcolumn reaction for the hydrophilic interaction liquid chromatography determination of memantine utilizing a silica hydride stationary phase. J Sep Sci 39:3145-3155. https://doi.org/10.1002/jssc.201600489

10. Jing SJ, Li QL, Jiang Y (2016) A new simultaneous derivatization and microextration method for the determination of memantine hydrochloride in human plasma. J Chromatogr B-Anal Technol Biomed Life Sci 1008:26-31. https://doi.org/10.1016/j.jchro mb.2015.09.016

11. USP (2009) USP 32-NF 27. Rockville

12. Konda RK, Challa BR, Chandu BR, Chandrasekhar KB (2012) Bioanalytical method development and validation of memantine in human plasma by high performance liquid chromatography with tandem mass spectrometry: application to bioequivalence study. J Anal Methods Chem. https://doi. org/10.1155/2012/101249

13. Bhateria M, Ramakrishna R, Pakala DB, Bhatta RS (2015) Development of an LC-MS/MS method for simultaneous determination of memantine and donepezil in rat plasma and its application to pharmacokinetic study. J Chromatogr B-Anal Technol Biomed Life Sci 1001:131-139. https://doi.org/10.1016/j.jchro mb.2015.07.042

14. Sawant TB, Mane DV (2017) To develop hplc method for the assay of memantine hydrochloride tablets using refractive index (RI) Detector. Indo Am J Pharm Sci 4:4391-4397. https:// doi.org/10.5281/zenodo.1064353

15. Sawant TB, Wakchaure VS, Rakibe UK, Musmade PB, Chaudhari BR, Mane DV (2017) The development and validation of novel, simple high-performance liquid chromatographic method with refractive index detector for quantification of memantine hydrochloride in dissolution samples. J Chromatogr Sci 55:603-609. https://doi.org/10.1093/chromsci/bmx013

16. Ganjali MR, Aboufazeli F, Riahi S, Dinarvand R, Norouzi P, Ghasemi MH, Kiani-Anbuhi R, Meftah S (2009) Memantine potentiometric membrane sensor for memantine pharmaceutical analysis; computational investigation. Int J Electrochem Sci 4:1138-1152

17. El Nashar RM, El-Tantawy ASM, Hassan SSM (2012) Potentiometric membrane sensors for the selective determination of memantine hydrochloride in pharmaceutical preparations. Int J Electrochem Sci 7:10802-10817

18. Merey HA, Helmy MI, Tawakkol SM, Toubar SS, Risk MS (2012) Potentiometric membrane sensors for determination of memantine hydrochloride and pramipexole dihydrochloride monohydrate. Portugaliae Electrochimica Acta 30:31-43. https ://doi.org/10.4152/pea.201201031

19. Lindner E, Gyurcsányi RE (2009) Quality control criteria for solidcontact, solvent polymeric membrane ion-selective electrodes. J Solid State Electrochem 13:51-68. https://doi.org/10.1007/ s10008-008-0608-1

20. Nikolskii BP, Materova EA (1985) Solid contact in membrane ionselective electrodes. Ion-Selective Electrode Rev 7:3-39

21. Hauser PC, Chiang DWL, Wright GA (1995) A potassium-ion selective electrode with valinomycin based poly(vinyl chloride) membrane and a poly(vinyl ferrocene) solid contact. Anal Chim Acta 302:241-248. https://doi.org/10.1016/0003-2670(94)00472 $-X$

22. Crespo GA, Macho S, Xavier Rius F (2008) lon-selective electrodes using carbon nanotubes as ion-to-electron transducers. Anal Chem 80:1316-1322. https://doi.org/10.1021/ac071156l

23. Crespo GA, Macho S, Bobacka J, Rius FX (2009) Transduction mechanism of carbon nanotubes in solid-contact ion-selective electrodes. Anal Chem 81:676-681. https://doi.org/10.1021/ ac802078z

24. Lai C-Z, Joyer MM, Fierke MA, Petkovich ND, Stein A, Buhlmann $P$ (2009) Subnanomolar detection limit application of ion-selective electrodes with three-dimensionally ordered macroporous (3DOM) carbon solid contacts. J Solid State Electrochem 13:123128. https://doi.org/10.1007/s10008-008-0579-2

25. Jaworska E, Lewandowski W, Mieczkowski J, Maksymiuk K, Michalska A (2013) Simple and disposable potentiometric sensors based on graphene or multi-walled carbon nanotubes carbon-plastic potentiometric sensors. Analyst 138:2363-2371. https://doi.org/10.1039/c3an36741j

26. Li F, Ye J, Zhou M, Gan S, Zhang Q, Han D, Niu L (2012) All-solidstate potassium-selective electrode using graphene as the solid contact. Analyst 137:618-623. https://doi.org/10.1039/c1an1 $5705 a$

27. Criscuolo F, Taurino I, Stradolini F, Carrara S, De Micheli G (2018) Highly-stable $\mathrm{Li}(+)$ ion-selective electrodes based on noble metal nanostructured layers as solid-contacts. Anal Chim Acta 1027:22-32. https://doi.org/10.1016/j.aca.2018.04.062

28. Zou XU, Cheong JH, Taitt BJ, Buehlmann P (2013) Solid contact ion-selective electrodes with a well-controlled Co(II)/ Co(III) redox buffer layer. Anal Chem 85:9350-9355. https://doi. org/10.1021/ac4022117

29. Zou XU, Zhen XV, Cheong JH, Buehlmann P (2014) Calibrationfree ionophore-based ion-selective electrodes with a $\mathrm{Co}(\mathrm{II}) /$ Co(III) redox couple-based solid contact. Anal Chem 86:86878692. https://doi.org/10.1021/ac501625z

30. Ishige Y, Klink S, Schuhmann W (2016) Intercalation compounds as inner reference electrodes for reproducible and robust solidcontact ion-selective electrodes. Angewandte Chemie-Int Edit 55:4831-4835. https://doi.org/10.1002/anie.201600111

31. Hu J, Stein A, Bühlmann P (2016) Rational design of all-solidstate ion-selective electrodes and reference electrodes. TrAC Trends Anal Chem 76:102-114. https://doi.org/10.1016/j. trac.2015.11.004

32. Umezawa Y, Buhlmann P, Umezawa K, Tohda K, Amemiya S (2000) Potentiometric selectivity coefficients of ion-selective electrodes Part I. Inorganic cations-(Technical report). Pure Appl Chem 72:1851-2082. https://doi.org/10.1351/pac2000721 01851 
33. Derar AR, Hussien EM (2019) Disposable multiwall carbon nanotubes based screen printed electrochemical sensor with improved sensitivity for the assay of daclatasvir: hepatitis c antiviral drug. IEEE Sens J 19:1626-1632. https://doi.org/10.1109/ JSEN.2018.2883656

34. Lai C-Z, Fierke MA, Stein A, Buehlmann P (2007) lon-selective electrodes with three-dimensionally ordered macroporous carbon as the solid contact. Anal Chem 79:4621-4626. https:// doi.org/10.1021/ac070132b

Publisher's Note Springer Nature remains neutral with regard to jurisdictional claims in published maps and institutional affiliations. 